http://jmscr.igmpublication.org/home/ ISSN (e)-2347-176x ISSN (p) 2455-0450 crossref DOI: https://dx.doi.org/10.18535/jmscr/v7i10.78

\title{
BPT bone versus Quadruple Hamstring Tendon Graft for Reconstruction of ACL injury based on the Clinical Outcome of the Patients
}

\author{
Authors \\ Dr ABM Zakir Uddin ${ }^{*}$, Dr Farzana Rabee Choudhury², Dr Abu Bakar Siddique ${ }^{3}$, \\ Dr Md Abul Hasnat ${ }^{4}$, Dr Md Mizanur Rahman ${ }^{5}$, Dr Md Shafiqul Islam ${ }^{6}$ \\ ${ }^{1}$ Assistant Professor (Orthopaedic Surgery), Mugda Medical College, Mugda, Dhaka, Bangladesh \\ ${ }^{2}$ Assistant Professor (Gynae and Obs), Mugda Medical College, Mugda, Dhaka, Bangladesh \\ ${ }^{3}$ Associate Professor (Orthopaedic Surgery), Ad-din Medical College, Dhaka, Bangladesh \\ ${ }^{4}$ Assistant Professor (Orthopaedic Surgery), Mugda Medical College, Mugda, Dhaka, Bangladesh \\ ${ }^{5}$ Assistant Professor (Orthopaedic Surgery), Mugda Medical College, Mugda, Dhaka, Bangladesh \\ ${ }^{6}$ Assistant Professor (Orthopaedic Surgery), Mugda Medical College, Mugda, Dhaka, Bangladesh \\ *Corresponding Author \\ Dr ABM Zakir Uddin
}

\begin{abstract}
Introduction: The knee is the most frequently injured joint because of its anatomic structure, its exposure to external forces and the functional demands placed on it. Knee injuries are often severely disabling unless diagnosed promptly and treated efficiently, and as such, the joint that is used to carry and to propel merits care on every account.

Objective: The present study is conducted to make a comparison of BPT bone versus quadruple hamstring tendon graft for reconstruction of ACL injury based on the clinical outcome of the patients.

Methodology: The study was carried out at National Institute of Traumatology and Orthopaedic Rehabilitation (NITOR), Sere-Banglanagar, Dhaka, Bangladesh, during the period from January 2006 to December 2007. A total of 19 patients meeting the above selection criteria were selected consecutively from the study population. The patients were divided into two groups (Group-I and Group-II), group-I consisting of ten (10) patients and group-I consisting of nine (9) patients based on the different treatment plans.

Results: Clinical evaluation 6 month after surgery showed no significantly deferent result between two groups, but slight better result in contest of knee flexion and lower thigh atrophy in the hamstring tendon group.

Conclusion: It is concluded that in the light of harvest site morbidity and post-operative stiffness associated with the patellar tendon graft, many surgeons look at other choices.

Keywords: BPT, ACL, Quadruple Hamstring Tendon Graft, Clinical Outcome.
\end{abstract}

\section{Introduction}

The knee is the most frequently injured joint because of its anatomic structure, its exposure to external forces and the functional demands placed on it. ${ }^{1}$
The menisci and the ligaments of the knee sustain injury mainly in sports, like football, volleyball, long jump, etc. The commonest damaging force is a combined rotation and impact injury to the bent weight-bearing knee, though at times a direct 
trauma to a flexed knee is also responsible. Knee injuries are often severely disabling unless diagnosed promptly and treated efficiently, and as such, the joint that is used to carry and to propel merits care on every account. Arthur J. Helfet in his book "Disorders of the knee" Emphasizes on this point when he says, "The knee is used to carry and to propel, to comfort and to supplicate, and merits care on every account.

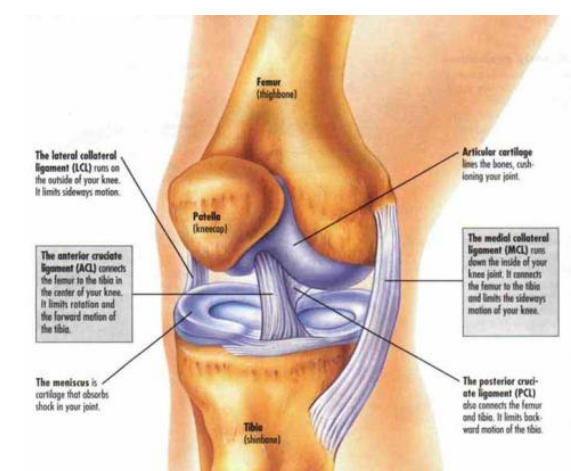

Figure 1: The menisci and the ligaments of the knee.

"Anterior cruciate ligament (ACL) is an intraarticular structure of knee joint. The ACL is an two-bundle ligament, consisting of a small anteromedial and a larger posterolateral bundle, a description which has been accepted as a basis for understanding the function of the ACL. ${ }^{2}$ Efforts to reconstruct an anterior cruciate ligament have resulted in the development of several different techniques, involving the use of prosthetic ligaments, autogenous grafts, and allografts composed of fascia lata, semitendinosus tendon, or patellar ligament. ${ }^{3}$

The present study makes a comparison of BPT bone versus quadruple hamstring tendon graft for reconstruction of ACL injury based on the clinical outcome of the patients.

\section{Objectives}

\section{Main Objective}

To make a comparison of BPT bone versus quadruple hamstring tendon graft for reconstruction of ACL injury based on the clinical outcome of the patients.

\section{Specific Objectives}

- To compare preoperative physical state of the two groups.

- To compare the post-operative subjective evaluation between two groups.

- To compare the clinical evaluation between two groups.

- To assess and compare the post-operative complications of the two groups.

\section{Methodology}

It was a prospective randomized controlled clinical study using the data through ongoing research.

The study was carried out at National Institute of Traumatology and Orthopaedic Rehabilitation (NITOR), Sere-Banglanagar, Dhaka, Bangladesh, during the period from January 2006 to December 2007. A total of 19 patients meeting the above selection criteria were selected consecutively from the study population. The patients were divided into two groups (Group-I and Group-II), group-I consisting of ten (10) patients and group-I consisting of nine (9) patients, e.g.

$\Rightarrow$ Group-I: Patient treated by BPT (Bone Patella Tendon) bone graft

$\Rightarrow$ Group-II: Patient treated by Quadruple Hamstring graft

\section{Inclusion and Exclusion Criteria}

The patients with following criteria were included in the study. First, patients that were aged between 18 to 40 years. Second, anterior cruciate ligament injury leading to instability of knee which had persisted for at least 3 months and failed to respond to conservative treatment including exercises for strengthening of quadriceps.

Patients who have a history of diabetes mellitus or random blood sugar $>11.1 \mathrm{mmol} / \mathrm{L}$, Patients with a history of previous reconstruction of the anterior cruciate ligament (ACL), who had a reconstruction for posterior, posterolateral or lateral instability of the knee and Patients who had meniscus injury are excluded from the study. 


\section{Clinical Assessment}

? A complete history was taken with particular emphasis on duration, cause and mechanism of injury.

? A thorough clinical examination was carried out and associated systemic medical illness like diabetes mellitus, hypertension and constitutional symptoms were noted.

? Detailed local examination was carried out.

\section{Radiological Assessment}

Good quality anteroposterior and lateral views to detect any associated fracture in the knee.

\section{Results}

Among 19 patients with the anterior cruciate ligament injury, the age range was 18 to 35 years. All of the patients are male. Mean age $=26.31( \pm$ 6.40) years. (Table-I)

Table-1: Age and distribution of the cases

\begin{tabular}{|l|c|c|c|c|}
\hline Age groups & $\begin{array}{c}\text { Group -1 BPT } \\
\text { Bone graft }\end{array}$ & $\begin{array}{c}\text { Percentage } \\
\mathbf{\%}\end{array}$ & $\begin{array}{c}\text { Group -2 Quadruple } \\
\text { Hamstring }\end{array}$ & $\begin{array}{c}\text { Percentage } \\
\mathbf{\%}\end{array}$ \\
\hline $11-20 \mathrm{y}$ & 03 & 30 & 02 & 22 \\
\hline $21-30 \mathrm{y}$ & 03 & 30 & 03 & 33 \\
\hline $31-40 \mathrm{y}$ & 04 & 40 & 04 & 44 \\
\hline Total & 10 & $100 \%$ & 09 & $100 \%$ \\
\hline
\end{tabular}

Table- 2 shows the preoperative state of the studied 19 patients from two groups.

Table 2 Distribution of patients by preoperative findings $(n=19)$

\begin{tabular}{|c|c|c|}
\hline Baseline Finding & $\begin{array}{l}\text { BPT Bone } \\
\text { graft }(\%)\end{array}$ & $\begin{array}{c}\text { Quadruple hamstring } \\
\text { graft }(\%)\end{array}$ \\
\hline \multicolumn{3}{|l|}{ Previous procedure done } \\
\hline Diagnostic arthoscopy & $02(20)$ & $01(110)$ \\
\hline None & $08(80)$ & $08(89)$ \\
\hline \multicolumn{3}{|l|}{ Lachman test } \\
\hline Grade II & $07(70)$ & $06(66)$ \\
\hline Grade III & $03(30)$ & $03(34)$ \\
\hline \multicolumn{3}{|l|}{ Pivot shift test } \\
\hline Positive & $06(60)$ & $05(56)$ \\
\hline Negative & $04(40)$ & $04(44)$ \\
\hline Meniscus injury & $03(30)$ & $03(33)$ \\
\hline Extension of knee $\left({ }^{\circ}\right)$ & $10(100)$ & $09(100)$ \\
\hline \multicolumn{3}{|l|}{ Flexion of knee $\left({ }^{\circ}\right)$} \\
\hline 130 & $03(30)$ & $04(44)$ \\
\hline 135 & $07(70)$ & $05(56)$ \\
\hline \multicolumn{3}{|l|}{ Category of patient } \\
\hline High risk of giving way & $01(10)$ & 00 \\
\hline Moderate risk of giving way & $09(90)$ & $01(10)$ \\
\hline $\begin{array}{l}\text { Lysholm knee scoring scale } \\
\text { Preoperative(mean) }\end{array}$ & $59.9 \%$ & $56.22 \%$ \\
\hline
\end{tabular}


The post-operative subjective evaluation has been detailed in the Table III below;

Table 3: Comparison of Subjective evaluation Parameters (n-19)

\begin{tabular}{|l|c|c|c|c|c|}
\hline Post-operative evaluation & $\begin{array}{c}\text { BPT bone } \\
\text { graft (n) }\end{array}$ & $\mathbf{\%}$ & $\begin{array}{c}\text { Quadruple Hamstring } \\
\text { graft (n) }\end{array}$ & $\mathbf{\%}$ & P value \\
\hline Influence of activity level $^{\mathrm{a}}$ & & & & & \\
A & 05 & 50 & 05 & 56 & \\
B & 05 & 50 & 04 & 44 & 0.82 \\
C & 00 & 00 & 00 & 00 & \\
\hline Function of the knee & & & & & \\
A & 05 & 50 & 05 & 56 & \\
B & 05 & 50 & 04 & 44 & 0.82 \\
C & 00 & 00 & 00 & 00 & \\
\hline Pain & & & & 78 & \\
A & 07 & 70 & 07 & 22 & 0.89 \\
B & 03 & 30 & 02 & 00 & \\
C & 00 & 00 & 00 & 67 & \\
\hline Swelling & 05 & 50 & & 33 & 0.64 \\
A & 05 & 50 & 06 & 00 & \\
B & 00 & 00 & 00 & 100 & --- \\
C & & & & & \\
\hline Giving way & 10 & 100 & 09 & \\
A & 00 & 00 & 00 & \\
B & & & & \\
\end{tabular}

Clinical evaluation 6 month after surgery showed no significantly deferent result between two groups, but slight better result in contest of knee flexion and lower thigh atrophy in the hamstring tendon group.

Table 4: Outcome of clinical evaluation

\begin{tabular}{|c|c|c|c|c|c|}
\hline & \multicolumn{2}{|c|}{$\begin{array}{l}\text { BPT Bone graft } \\
\text { group }\end{array}$} & \multicolumn{2}{|c|}{$\begin{array}{c}\text { Quadruple } \\
\text { Hamstring group }\end{array}$} & \multirow[t]{2}{*}{ P value } \\
\hline & $\mathbf{N}$ & $\%$ & $\mathbf{N}$ & $\%$ & \\
\hline \multicolumn{6}{|c|}{ Lachman test } \\
\hline Grare-1 & 07 & 70 & 08 & 89 & \multirow[t]{2}{*}{0.58} \\
\hline Grade-2 & 03 & 30 & 01 & 11 & \\
\hline \multicolumn{6}{|c|}{ Pivot shift test } \\
\hline A & 08 & 80 & 08 & 89 & \multirow[t]{2}{*}{0.54} \\
\hline $\mathrm{B}$ & 02 & 20 & 01 & 11 & \\
\hline \multicolumn{6}{|c|}{ Medial joint opening } \\
\hline A & 08 & 80 & 08 & 89 & \multirow[t]{2}{*}{0.54} \\
\hline $\mathrm{B}$ & 02 & 20 & 01 & 11 & \\
\hline \multicolumn{6}{|c|}{ Group rating for ligament examination } \\
\hline A & 08 & 80 & 08 & 89 & \multirow[t]{2}{*}{0.54} \\
\hline $\mathrm{B}$ & 02 & 20 & 01 & 11 & \\
\hline \multicolumn{6}{|l|}{ Effusion } \\
\hline $\mathrm{A}$ & 09 & 90 & 09 & 100 & \multirow[t]{2}{*}{0.52} \\
\hline $\mathrm{B}$ & 01 & 10 & 00 & 00 & \\
\hline \multicolumn{6}{|c|}{ Extension } \\
\hline $\mathrm{A}$ & 09 & 90 & 09 & 100 & \multirow[t]{2}{*}{0.52} \\
\hline B & 01 & 10 & 00 & 00 & \\
\hline \multicolumn{6}{|l|}{ Flexion } \\
\hline $\mathrm{A}$ & 08 & 80 & 08 & 89 & \multirow[t]{2}{*}{0.54} \\
\hline $\mathrm{B}$ & 02 & 20 & 01 & 11 & \\
\hline \multicolumn{6}{|c|}{ Thigh atrophy } \\
\hline $\mathrm{A}$ & 04 & 40 & 06 & 67 & \multirow[t]{2}{*}{0.24} \\
\hline B & 06 & 60 & 03 & 33 & \\
\hline
\end{tabular}


Table 5 describes the post-operative complications of the patients.

Table 5: Post-operative complications

\begin{tabular}{|l|c|c|c|c|c|}
\hline Complication & \multicolumn{2}{|c|}{$\begin{array}{c}\text { Group-1 (BPT } \\
\text { Bone graft) }\end{array}$} & \multicolumn{2}{c|}{$\begin{array}{c}\text { Group-2 (Quadruple } \\
\text { Hamstring graft) }\end{array}$} & P value \\
\hline & $\mathrm{N}$ & $\%$ & $\mathrm{~N}$ & $\%$ & \\
\hline Wound infection & 00 & 00 & 00 & 00 & - \\
\hline $\begin{array}{l}\text { Anterior knee pain (Patello-femoral } \\
\text { tenderness) }\end{array}$ & 04 & 40 & 01 & 11 & 0.30 \\
\hline Kneeling pain & 04 & 40 & 01 & 11 & 0.30 \\
\hline Joint effusion & 00 & 00 & 00 & 00 & - \\
\hline Joint swelling & 03 & 30 & 02 & 22 & 0.89 \\
\hline Joint stiffness & 02 & 20 & 01 & 11 & 0.92 \\
\hline Knee instability & 00 & 00 & 00 & 00 & - \\
\hline Decrease skin sensitivity & 05 & 50 & 01 & 11 & 0.34 \\
\hline Thigh wasting & 03 & 30 & 02 & 22 & 0.89 \\
\hline Graft failure & 00 & 00 & 00 & 00 & - \\
\hline
\end{tabular}

Data analysis done by Chi-squares test (Fisher exact test)

\section{Discussion}

It was observed in the study that a total of 19 patients meeting selection criteria were consecutively selected for study. Mean age of patients was 26. The data were collected using a structured questionnaire which addressed all the variable of interest. The test statistics use to analyze the data were descriptive statistics, Chisquare Test, Fisher's Extract probability Test and Wilcoxon Signed Rank test. About half of the subjects of both groups were service holder and both knee affected equally in both groups. Fifty percent patient reported within six months of the injury. All the patients had either Grade-II or Grade-III positive Lachman test. Associate meniscus injury was present in $30 \%$ cases. All of them had full extension of knee at baseline in both groups. Sixty percent of the patients in group-I \& fifty six percent of the patient in group-II had positive Pivot shift test. In contest of preoperative range of motion $70 \%$ had $135^{\circ}$ flexion and $30 \%$ had $130^{\circ}$ flexion of knee in BPT Bone graft group. On the other hand $56 \%$ had $135^{\circ}$ flexion and $44 \%$ had $130^{\circ}$ flexion of knee in Quadruple hamstring group respectively. Preoperative Lyshom score mean was 59.9SD \pm 7.07 in BPT Bone graft and the score was $56.22 \mathrm{SD} \pm 6.01$ in Quadruple hamstring group.

In contest of clinical evaluation, preoperative versus postoperative Lachman test showed a significant improvement in both groups. Six month after surgery, slight better result was obtained in contest of knee flexion and lower thigh atrophy in the hamstring tendon group than BPT bone graft. Two year after surgery. Other clinical evaluation showed no significant different between two groups.

Postoperative complication showed no significant different result between two groups except BPT bone graft group had slight increased patellofemoral tenderness and donor site morbidity (kneeling pain and decreased sensation over the knee). There were significantly less positive pivotshift test results in the hamstring tendon group $(P=.005)$, and hamstring tendon patients showed lower thigh atrophy $(P=.024)$ and patell of emoral crepitus $(P=.003)^{4}$. Fewer patients complaining of difficulty jumping (3\% vs $17 \%, \mathrm{P}$ $=.03)$, and a greater number of patients returning to preinjury Tegner level ( $51 \%$ vs $26 \%, \mathrm{P}=.01$ ). The quadruple-strand semitendinosus/gracilis group had better extension strength in the operated leg than in the non operated leg $(92 \%$ vs $85 \%, \mathrm{P}=$ $.04)$, fewer patients with sensory deficits (14\% vs $83 \%, \mathrm{P}=.0001)$, and fewer patients with difficulty kneeling (6\% vs $20 \%, \mathrm{P}=.04)^{5} .26 \%$ of the patients troublesome due to patellofemoral pain 6. Regarding kneeling pain after reconstruction with the hamstring tendon auto graft was significantly less common than with the patellar tendon auto graft ${ }^{7}$. 


\section{Conclusion}

It is concluded that In the light of harvest site morbidity and post-operative stiffness associated with the patellar tendon graft, many surgeons look at other choices, like semi-tendinosus graft. With the improvement in the technique of the preparation of the multiple bundle graft, now a day's semi-tendinosus graft has become more popular.

\section{References}

1. Miller III, RH 2003, "Knee Injuries", In Campbells's operative Orthopaedics, vol.3, $10^{\text {th }}$ ed, Mosby, p. 2166.

2. Amis, AA, Dawkins, GPC 1991, "Functional Anatomy of Anterior Cruciate Ligament- Fibre Bundle Action Related to Ligament Replacement and Injury", The Journal of Bone and Joint Surgery (Br), vol. 73-B, pp. 260-7.

3. Buss, DD, Warren, RF, Wickiewicz, TL, Galinat, BJ, Panariello, R 1993, "Arthroscopically Assited reconstruction Anterior Cruciate Ligament Graft", The Journal of Bone and Joint Surgery, vol. 75A (9), pp.1346- 55.

4. Wagner, M, Schallock, J, Hass, N \& Weiler, A 2005, " Hamstring tendon Anterior Cruciate Ligament Reconstruction Using Biodegradable Interference fit Fixation " The American Orthopaedic Society for Sports Medicine, vol.33, no. 9, pp. 1327-1336.

5. Maletis, GB, Cameron, SL, Tengan, JJ \& Burchette RJ 2007, "A Prospective Randomized Study of Anterior Cruciate Ligament Reconstruction- A Comparison of Patellar Tendon and Quadruple- Strand semitendinosus/ Gracilis Tendons Fixed With bioabsorbable Interference Screws" The American Orthopaedic Society for Sports Medicine, vol.33, no.9, pp.13271336.
6. Liden, M, Ejerhed, L,Sernert, N, Laxdal, G \& Kartus, J 2007, "Patellar Tendon or Semitendinosus Tendon Autografts for Anterior Cruciate Ligament Reconstruction A Prospective, Randomized Study With a 7-Year Followup" The American Journal of Sports Medicine", vol. 35, pp. 740-748.

7. Corry, IS, Webb, JM, Clingeleffer, AJ, Pinczewski, LA.1999, "Arthroscopically Reconstruction Anterior Cruciate Ligament : a comparison of patellar tendon autograft and Four- strand hamstring tendon autograft", Am J Sports Med, vol. 27, pp.444-454. 